\title{
ARTE Y PATRIMONIO: OBJETOS EN DESUSO
}

Recibido: 29-08-2016

Aprobado: 14-10-2016

\author{
Emmanuel Zúñiga Salas \\ Escuela de Artes Plásticas, Universidad de Costa Rica
}

Emanuel Zúñiga Salas.
Artista costarricense, cursa el
último año de la carrera Diseño
Pictórico en la Escuela de Artes
Plásticas, UCR. Cuenta con una
exposición individual (2014) en la
Sala poligráfica de TEOR/éTica,
ha participado en exposiciones
colectivas como el "Abierto
nacional de grabado" (2013) en
la Galería Nacional y "Mi
memoria es una mierda" (2016)
en el Museo de Arte y Diseño
Contemporáneo. Actualmente
participa en el taller "Tocar, no
dominar" como parte de la X
Bienal Centroamericana.

\begin{abstract}
RESUMEN
Cuando entramos a un museo el silencio predomina, incluso en ocasiones el guarda de seguridad nos pide que mantengamos una distancia prudente con el objeto que estamos observando; hay que tenerle respeto a nuestros antepasados, lo que queda de ellos es valioso. La obra de arte, a nivel histórico o económico, tradicionalmente ha sido considerada como uno de estos objetos: importante para nuestra sociedad, de hecho, en ocasiones se le ha visto poderes místicos. Sin embargo, si alzamos la mirada también podremos notar que hay muy pocas personas visitando la exposición, los fantasmas que ahí habitan no le preocupan a nadie; el museo parece un santuario de símbolos que nadie recuerda ¿por qué? ¿cuál sería entonces la función del artista dentro de nuestra sociedad? ¿cuáles son los valores que determinan si un objeto de este tipo es valioso o no? El presente ensayo busca ahondar en algunas maneras en que la cultura nos confronta con representaciones de lo que somos y de cómo la producción cultural transforma nuestros modos de ver y actuar en el mundo.
\end{abstract}

\section{ABSTRACT}

When we walk into a museum silence prevails, even sometimes the security guard asks us to keep a safe distance to the object we are observing; we must have respect for our ancestors, what remains of them is valuable. The work of art, in a historical or economic level, has traditionally been considered one of these objects: important for our society, indeed, sometimes they have been seen mystical powers. However, if we raise our eyes we can also note that there are very few people visiting the exhibition, the ghosts that live there do not care to anyone; the museum looks like a shrine of symbols that nobody remembers. Why? What would then be the role of the artist in our society? What are the values that determine whether an object of this type is valuable or not? This essay seeks to delve into how culture confronts us with representations of what we are and how cultural production transforms our ways of seeing and acting in the world.

Palabras clave: Prácticas culturales, museo, artista, producción cultural, representación. Keywords: Cultural practices, museum, artist, cultural production, representation. 
Probablemente no habría cultura si los seres humanos no fueran conscientes de su mortalidad.

Zygmunt Bauman

En el primer ciclo lectivo del 2016 he debido llevar distintos cursos que por varias razones convergen en lo que entendemos hoy por cultura; en las lecturas asignadas se muestran diferentes estrategias para entender este fenómeno y se dan a conocer algunos de los métodos que se utilizan para trabajar la cultura. Las ideas ahí expuestas me han permitido pensarme más que como artista, como productor cultural.

En un seminario tuve la oportunidad de leer el primer capítulo de un libro titulado Gestión del patrimonio cultural (Barcelona 2001), escrito por Josep Ballart y Jordi Juan i Tresserras. De ese capítulo, más allá de los procesos de selección históricos o administrativos, me llamó poderosamente la atención cómo los autores buscaban la manera de categorizar las cualidades y virtudes de un objeto potencialmente patrimonial a partir de un sistema de valores que determinara por qué ese objeto era valioso.

El presente ensayo constituye un esfuerzo por profundizar en la noción de patrimonio cultural, a partir de la puesta en tensión del texto mencionado junto con una exposición de artistas visuales costarricenses titulada "La ineludible muerte", que se lleva a cabo en los Museos del Banco Central (febrero-agosto 2016). Cabe agregar que para efectos de este ejercicio no en vano hemos decidido problematizar dicho texto con una exposición de arte; esta decisión busca facilitar los procesos de análisis y permitir enfocarnos en el sistema de valores que dictan qué es y qué no es patrimonio. En otras palabras, al asegurarnos de que lo que estamos observando es patrimonio cultural, el panorama se nos aclara y podemos adentrarnos en la noción de obra de arte tratando de entender por qué un objeto de este tipo es importante para nosotros como sociedad. 


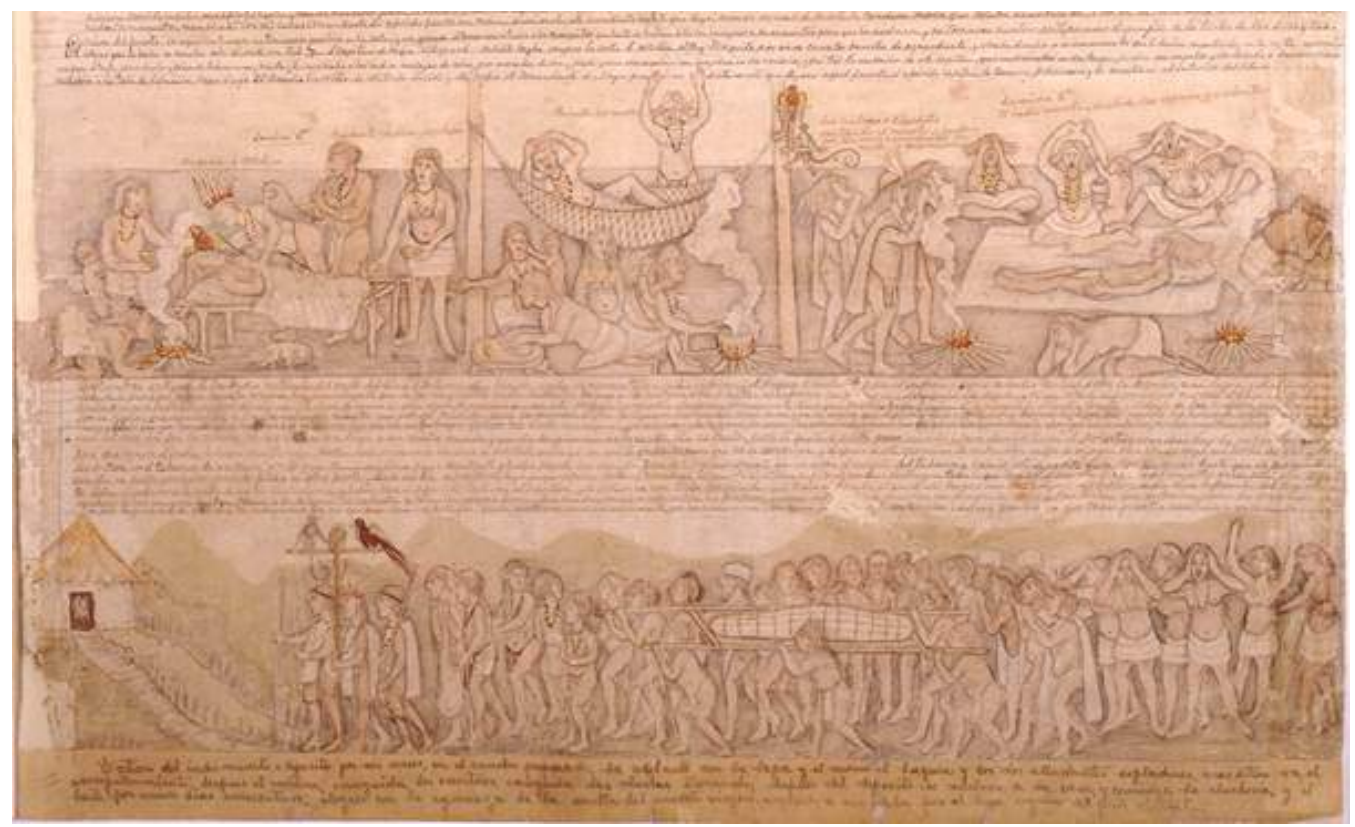

[Fig. 1] José María Figueroa (1820-1900).

Entierro del indio muerto o depositado por seis meses en el rancho preparado. Álbum de Figueroa, I, F. 11F. Finales del siglo XIX.

Colección Archivo Nacional de Costa Rica.

Una de las grandes ventajas de vivir en Costa Rica es que la cultura está ahí, de hecho, solamente tenemos que desplazarnos al centro de San José, pasar frente al Teatro Nacional, cruzar la Plaza de la Cultura y bajar a los Museos del Banco Central para comenzar nuestra búsqueda. De esta forma podemos constatar que la "alta" cultura y la cultura "popular" son una sola (¿dos caras de la misma moneda?) y que luego de haber visto imágenes precolombinas, reproducciones del álbum de Figueroa, altares, fotografías de la guerra del 48, vírgenes, pinturas y dibujos nos iremos a casa caminando entre músicos, palomas, punks y estatuas vivientes...

De vuelta en el museo, la ALTA cultura hace que nuestra integridad física y moral se sienta protegida, tanto así que no dudamos por un instante que lo que vamos a ver es patrimonio cultural (¿Cómo no, si está en el MUSEO?). Lo que está ahí es importante, son obras de arte, y según los autores Ballart y Tresserras, "los objetos artísticos reciben una consideración especial ya que escapan a toda posible categorización" (Ballart, 2001: p. 21). Pero ver a la obra de arte como algo inclasificable, es situarla en un lugar en donde nadie o casi nadie puede llegar, es algo inexplicable es... presentarla como un objeto sin utilidad alguna, ajeno a nosotros. Entonces, ¿qué produce la 
cultura y por ende el artista? ¿Cómo algo ajeno a nosotros puede llegar a ser importante para nuestro grupo social? Parece ser que estamos aquí en una contradicción.

Esta "consideración especial" que mencionan los autores evita que nos enfrentemos al problema que presenta la obra de arte y también demos por sentado que lo que es, así es. No hay posibilidad de reflexionar ni de cuestionar, como estar frente a una verdad absoluta: obra del genio creativo. Por otro lado, si nos alejamos de esta concepción y entendemos la obra de arte como una puesta en abismo, se puede decir que un producto cultural es un objeto informado (simbólico) que no está a salvo del tiempo, sino que resguarda a este dentro de sí, de hecho, es una herramienta para incidir una y otra vez en la realidad por medio de la re-presentación de conceptos. El concepto de muerte, por ejemplo.
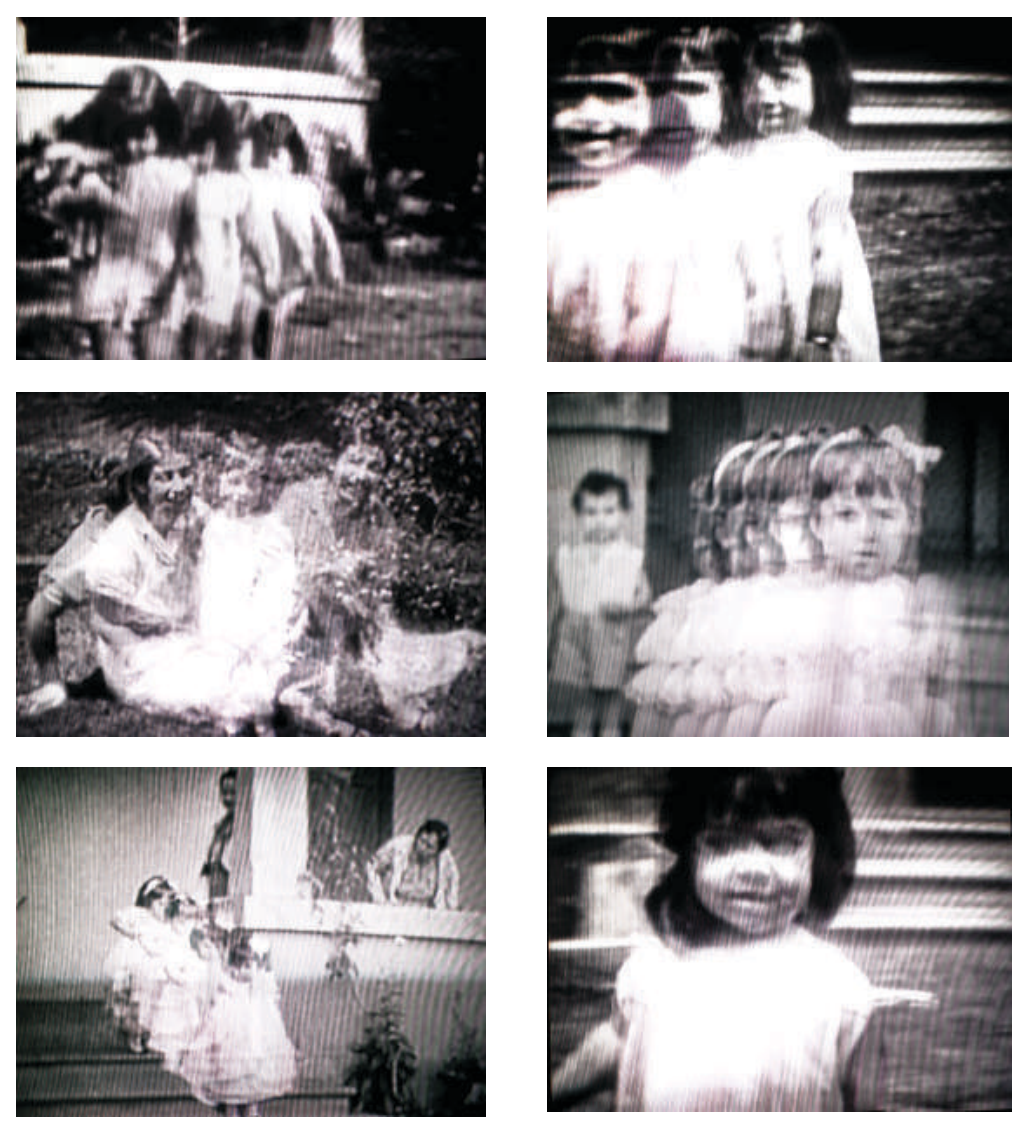

[Fig. 2] Elisa Bergel Melo (1989).

Recuerdo/Retorno. Fotografía digital, políptico. 30 × 21 cm c/u. 2014 .

Propiedad de la artista. 

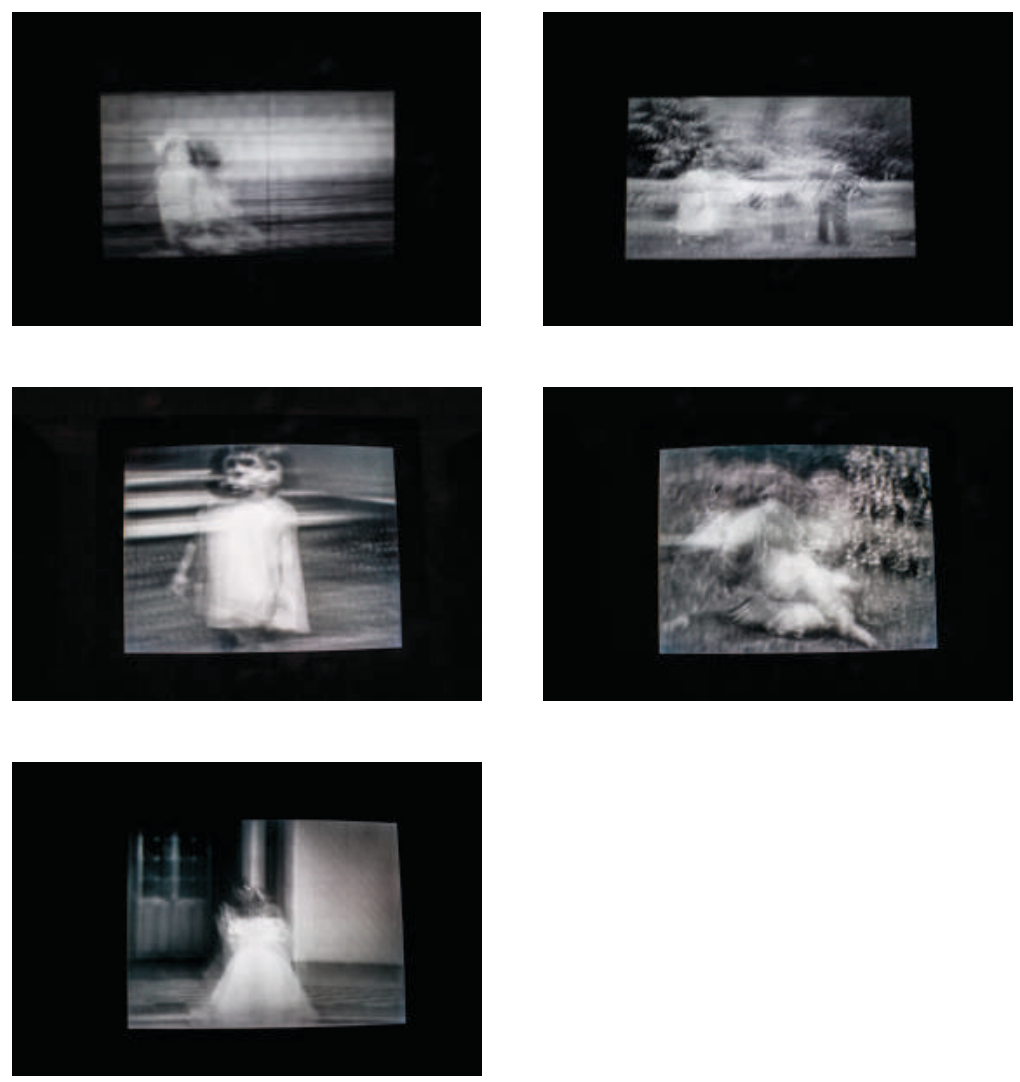

[Fig. 3] Elisa Bergel Melo (1989). Recuerdo/Retorno.

Fotografía digital, políptico. $30 \times 21 \mathrm{~cm}$ c/u. 2014. Propiedad de la artista.

Con esta definición queda claro que estamos dejando de lado los productos efímeros o intangibles de la cultura, expresiones que van más allá del objeto y responden al pensamiento mágico, hablamos aquí de rituales, cantos, danzas, y demás artes performativas, pero también de archivos digitales como las imágenes JPG; las cuales evidencian que hablar de la obra de arte en términos singulares, como un objeto único e irrepetible, cada vez más pierde sentido. Lamentablemente, esta metamorfosis de la producción artística tiene como consecuencia que las prácticas culturales comúnmente se vean como actividades con fines únicamente recreativos o de ayuda social y su producción material como un souvenir, una especie de añoranza sin valor práctico que supuestamente nos transforma.

Ahora bien, con todo esto lo que hemos tratado de ir haciendo es una especie de mapa, una guía que nos ayude a llegar a ese lugar supuestamente imposible de categorizar, para alegar que esa categoría ("inexistente") es la realidad misma, nuestras prácticas, 
modos de vivir y entender el mundo. Por ende, podemos afirmar que el artífice o productor cultural no es una especie de genio creativo ni tampoco trabaja en absoluta soledad, hoy en día el artista es un investigador visual, produce conocimiento y trabaja con nosotros, entre nosotros. Su principal función es la de representar, esto es: hacer visible, comunicable la información de un concepto o una idea; "la imaginación es la capacidad específica de crear y descifrar imágenes" (Flusser, 2001 p. 80). También podemos aseverar que la función de un producto cultural se desarrolla en lo simbólico, en la producción de sentido. De esta manera tomamos conciencia de que una exposición de objetos artísticos es solamente la puerta de entrada hacia algo más amplio, algo que busca comunicarse, que pide ser actualizado; una exposición es una estrategia para recordar.

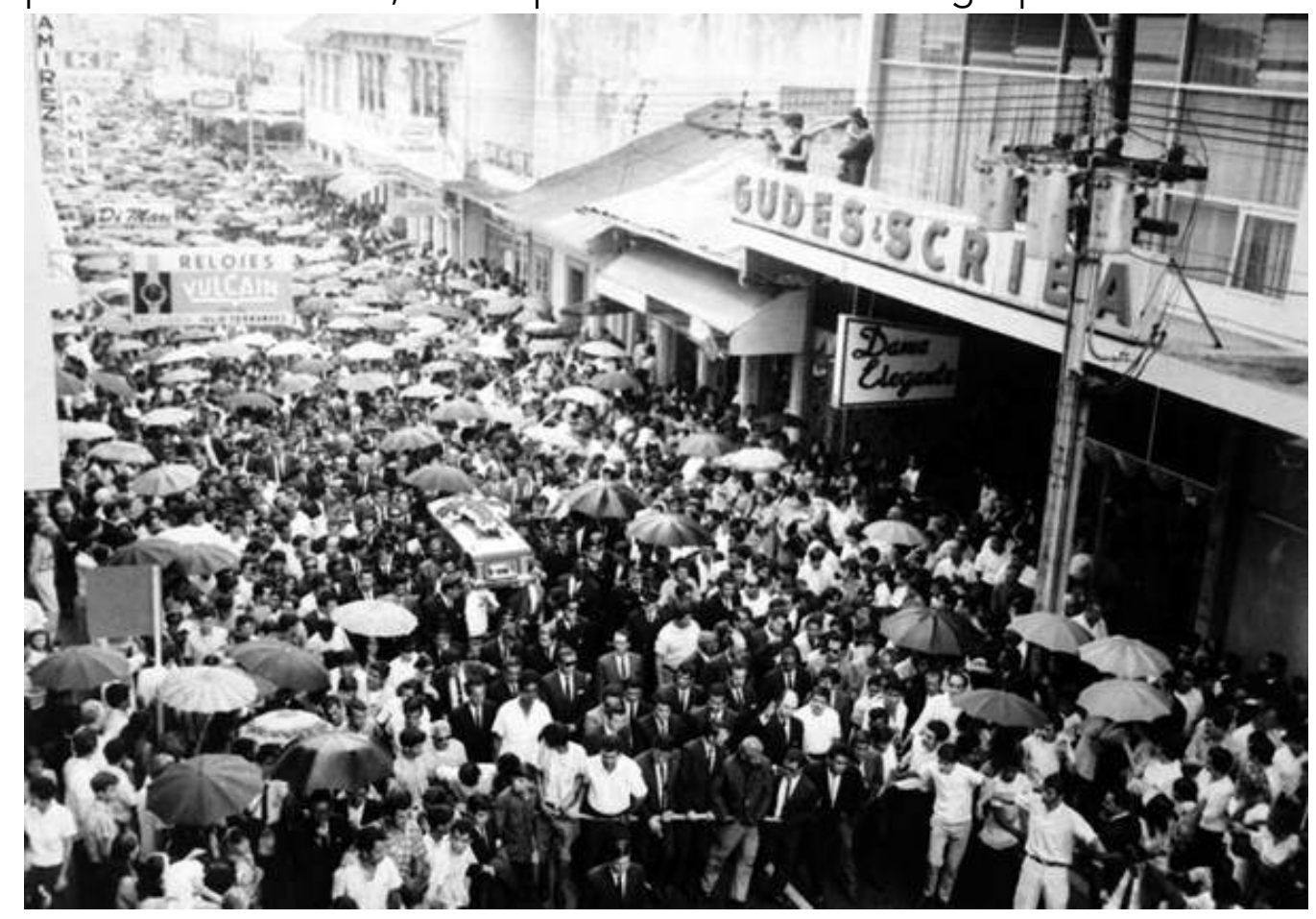

[Fig. 4] Funeral del Dr. Rafael Ángel Calderón Guardia, Presidente de la República (1940-1944). San José, Costa Rica, 11 de junio de 1970. Colección Archivo Nacional de Costa Rica.

Afortunadamente para nosotros, varias de estas nociones están tomadas en cuenta en el trabajo curatorial de María José Monge y Priscilla Molina, de hecho, podemos ver que cuando se refieren a representaciones no lo hacen pensando en ellas únicamente como obras de arte sino como imágenes en general: 
"La imagen es inherente a estos procesos; desde la imagen asociada a la realización de determinados rituales, pasando por la imagen artística, que suele dimensionar aspectos inusuales de la muerte, hasta la imagen mediática que, desde los puntos de vista documental, publicitario o recreativo, nos vincula con ella de diversas formas." (Monge, 2016: p. 4)

De esta manera, es claro que las curadoras buscan la forma de demostrarnos que el modo en que entendemos "la muerte es una construcción sociocultural, es el resultado de consideraciones médicas, psicológicas, filosóficas, éticas, religiosas o legales" (Monge, 2016: p. 4) sobre un concepto que hacemos visible a través de representaciones. Por lo tanto, dicha "exhibición incluye imágenes así de diversas, porque todas ellas, difícilmente, funcionan de forma aislada." (Monge, 2016: p. 4)

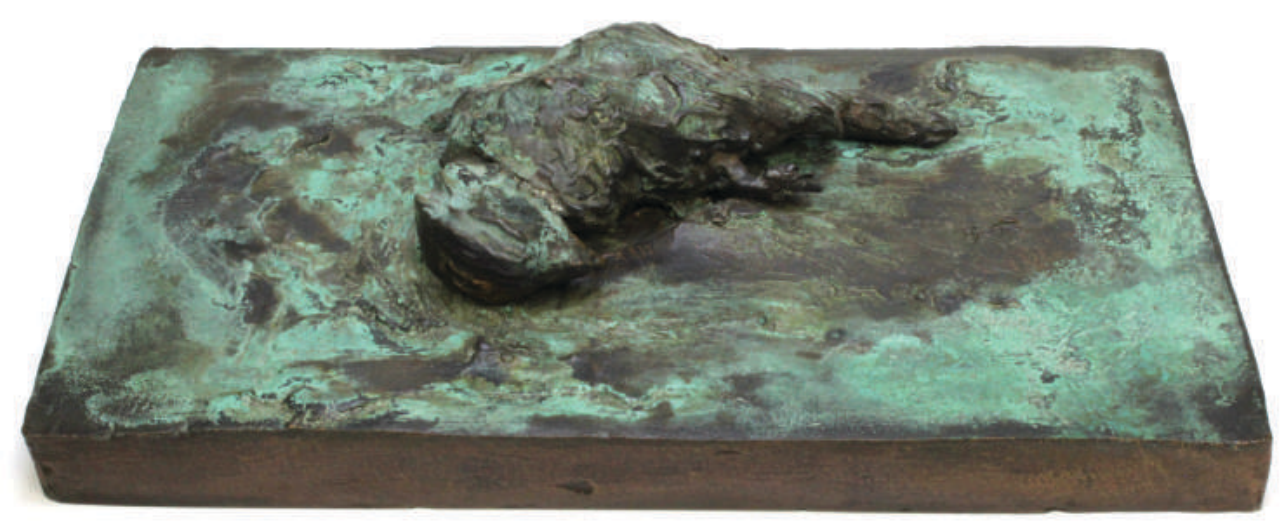

[Fig. 5] Marisel Jiménez (1947). Yigüirro. Fundición en bronce. $23 \times 12,5 \times 5,5 \mathrm{~cm}$. S. f. Colección del BCCR.

Ahora bien, para ir concluyendo este ensayo, podemos decir que de los tres tipos de valores que se proponen en el texto en cuestión ya nos hemos referido, aunque de manera no tan explícita, al valor de uso y al valor simbólico que pueda tener un producto cultural. Hemos dicho que la necesidad en concreto que satisface hacer o consumir un producto cultural es la de darle sentido a nuestra realidad ¿cómo? por medio de la actualización del pasado, ya sea revisando, representando o reactivando conceptos. También hemos mencionado que este proceso se desarrolla en lo simbólico, es decir, en la información que contienen dichos productos.

$Y$ es aquí donde entra el valor formal como un nudo para amarrar nuestro problema. Si ponemos atención la palabra informar connota el ejercicio de darle forma a algo, dotarlo de in-formación es una 
acción simbólica (hay quienes dicen que los artistas piensan con las manos). Al contrario de lo que dicen los autores sobre la forma, esta no puede ser evaluada en términos de buenos y malos, todos los materiales apelan directamente a los sentidos y sus posibilidades simbólicas son múltiples, la gracia (o creatividad) está en cómo los manipulamos para construir una idea coherente, la cual pasa por un uso "adecuado" de las herramientas y los métodos propios de una época. Es por esto que un producto artístico no puede variar su calidad dependiendo de si es feo o bonito, sino por la coherencia entre forma y contenido. Esa es su técnica.

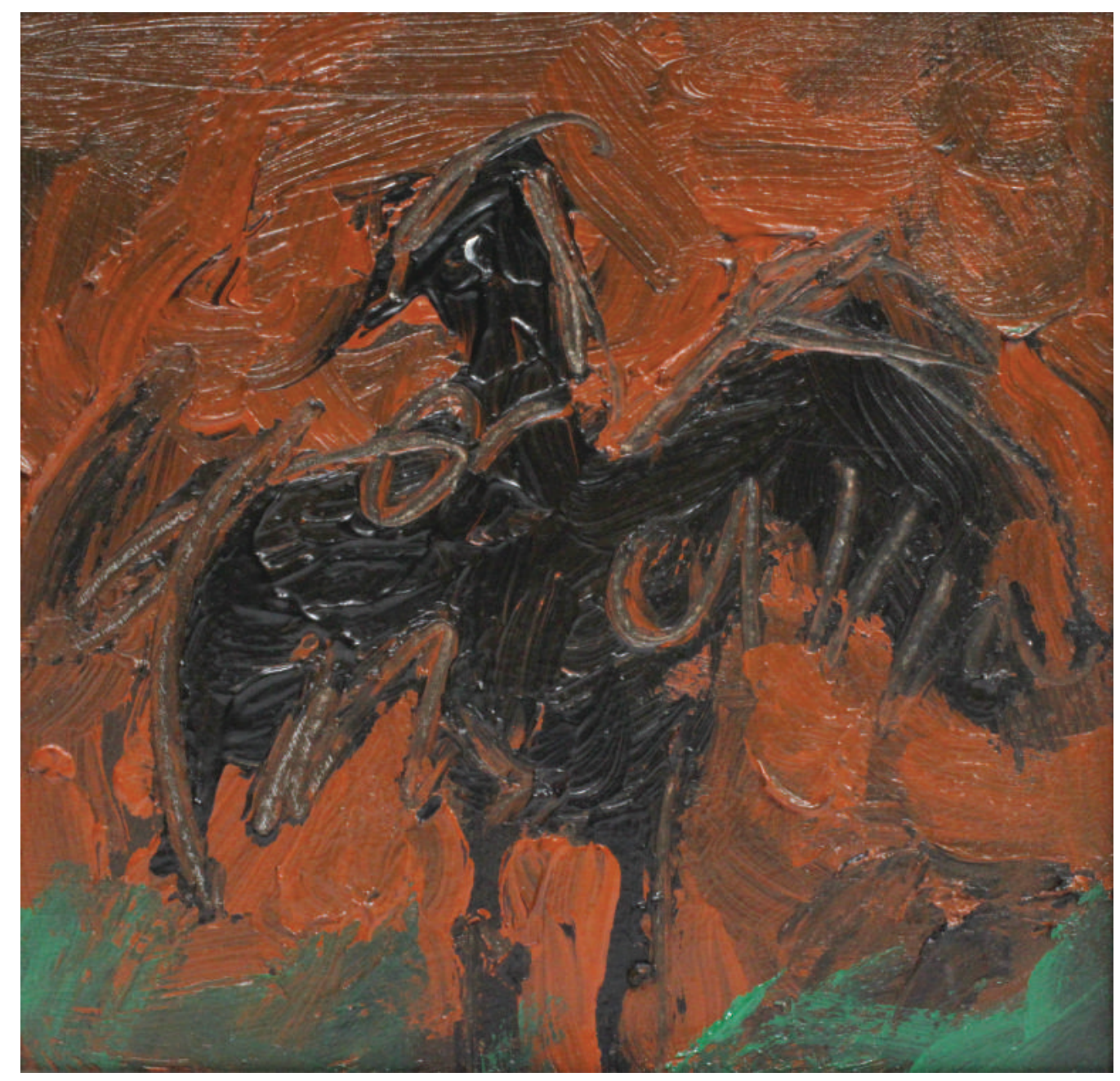

[Fig. 6] Manuel Zumbado (1964). Zopilote. Acrílico sobre tela. 40 x 41 cm. 1993. Colección del BCCR. 
Por el contrario, en una producción sin coherencia ni proceso, la ocurrencia toma partida y nos pone en situaciones en que ni el artista ni la obra son geniales. El proceso creativo es como un juego ${ }^{1}$ en el cual el artista manipula sus reglas, saca conclusiones y va sistematizando los resultados. La experimentación no se entiende como resultado del mero azar o producto de la "libertad creativa" del artista, esta obedece a un proceso de investigación.

En conclusión, los símbolos se comunican a través de su materialidad (en el sentido más amplio del término), su calidad es la coherencia entre argumento y técnica; relación que da fe de los procesos de pensamiento propios de una época y cómo estos afectan las maneras en que producimos el mundo. Sin embargo, contemplar objetos valiosos detrás de una vitrina no cambia nada, para poder comunicarse estos piden ser actualizados; nuestro trabajo consiste en re-formarlos. Entonces, trabajar con la cultura le presenta al artífice la posibilidad de actualizar la escala de valores que rige su propia producción; el cambio no se logra invocando imágenes de revoluciones pasadas, sino mediando su información, es decir, alterando las conexiones entre los símbolos. Que una acción sea ella misma la imagen.

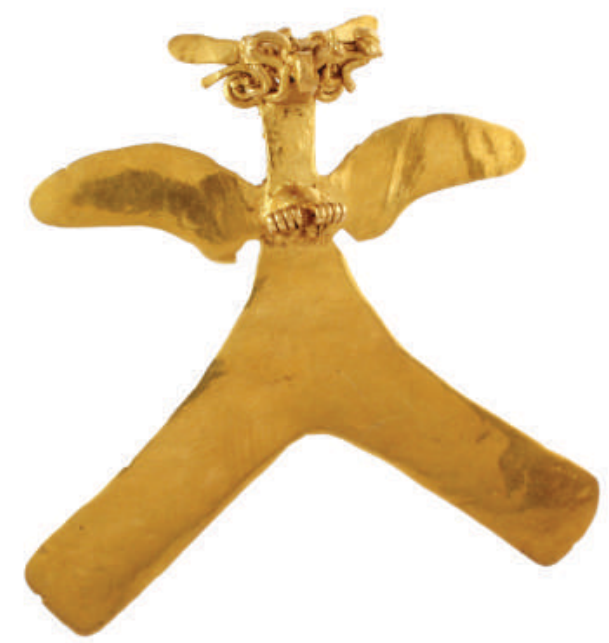

[Fig. 7] Colgante con figura de águila. Pacífico sur. 700-1550 d.C. $12 \times 13$ cm. BCCR-C-1274.

\footnotetext{
${ }^{1}$ Según Vilém Flusser, el juego es "una actividad que es un fin en sí" (2001: p. 80)
} 
Manipular la manera en que se tejen las relaciones entre lo que experimentamos (vemos) y lo que pensamos (imaginamos), transformando así nuestras prácticas, modos de vivir y entender el mundo; es por esto que la producción cultural es valiosa para nosotros: "son imágenes de nuestro pasado y de nuestro presente, de manera que, con mayor o menor nitidez, nos confrontan con algo de lo que somos, de quienes somos." (Monge, 2016: p. 4)

\section{Bibliografía}

Ballart, Josep, y Jordi Juan i Tresserras. (2001) Gestión del patrimonio cultural. Barcelona: Ariel.

Monge, María José; Molina, Priscilla. (2016) La ineludible muerte. San José: Museos del Banco Central de Costa Rica.

Bergel Melo, Elisa. Recuerdo/Retorno. 2014. Fotografía digital, políptico. La ineludible muerte. Ed. María José Monge Picado y Priscilla Molina Muñoz. San José: Fundación Museos del Banco Central de Costa Rica, 2015. 106 y 107. Cortesía de FMBCCR.

Desconocido. Colgante con figura de águila. 700-1550 d.C. Pacífico sur. La ineludible muerte. Ed. María José Monge Picado y Priscilla Molina Muñoz. San José: Fundación Museos del Banco Central de Costa Rica, 2015. 79. Archivo fotográfico FMBCCR.

Desconocido. Funeral del Dr. Rafael Ángel Calderón Guardia, Presidente de la República (1940-1944). 11 de junio de 1970. San José, Costa Rica. La ineludible muerte. Ed. María José Monge Picado y Priscilla Molina Muñoz. San José: Fundación Museos del Banco Central de Costa Rica, 2015. 70. Cortesía FMBCCR.

Figueroa, José María. Entierro del indio muerto o depositado por seis meses en el rancho preparado. Finales del siglo XIX. Álbum de Figueroa, I, F. 11F. La ineludible muerte. Ed. María José Monge Picado y Priscilla Molina Muñoz. San José: Fundación Museos del Banco Central de Costa Rica, 2015. 64. Cortesía de FMBCCR. 
Flusser, Vilém. (2001) Una filosofía de la fotografía. Madrid: Editorial Síntesis.

Jiménez, Marisel. Yigüirro. S.f. Fundición en bronce. La ineludible muerte. Ed. María José Monge Picado y Priscilla Molina Muñoz. San José: Fundación Museos del Banco Central de Costa Rica, 2015. 83. Cortesía de FMBCCR.

Zumbado, Manuel. Zopilote. 1993. Acrílico sobre tela. La ineludible muerte. Ed. María José Monge Picado y Priscilla Molina Muñoz. San José: Fundación Museos del Banco Central de Costa Rica, 2015. 24. Cortesía de FMBCCR. 